\title{
Interleaved High Step-Up Converter With Coupled Inductor and Voltage Multiplier for Renewable Energy System
}

\author{
Xing Liu, Xiao Zhang, Xuefeng Hu, Hao Chen, Lezhu Chen, and Yujia Zhang
}

\begin{abstract}
The concepts of dual coupled inductors and voltage multiplier cell are integrated to derive a novel non-isolated interleaved high step-up boost converter in this paper. At the input, due to the interleaved dual coupled inductors and voltage multiplier cell, the converter inhibits current ripple and reduced voltage stress for the power devices; At the output, the secondary sides of the two coupled inductors are connected in series to achieve the purpose of much higher voltage gain and lower voltage stress on the power devices. Therefore, lower voltage rating MOSFETs and diodes can be selected to reduce both switching and conduction losses. In addition, the leakage inductance energy of two coupled inductors can be absorbed and recycled to the output, and the reverse-recovery problem of diodes can be effectively suppressed. Zero current switching (ZCS) turn-on is realized for the power switches to reduce the switching loss. The working principle and steady-state characteristics of the converter are analyzed in detail. The voltage balance of the output capacitors and input current sharing by two interleaved phases are realized through the double closed-loop control of voltage and current. Finally, a $400 \mathrm{~W}$ laboratory prototype with $25 \sim 30 \mathrm{~V}$ input and $400 \mathrm{~V}$ output is built to verify the significant improvements of the proposed converter.
\end{abstract}

Index Terms - Coupled inductor, high voltage gain, interleaved, voltage multiplier cell.

\section{INTRODUCTION}

$\mathrm{I}^{\mathrm{s}}$ recent years, there are increasing demand of high voltage gain DC-DC converters, which have been widely employed in some fields of industries, such as photovoltaic (PV) generation systems, fuel cells (FC) systems, hybrid electric vehicles, energy storage systems, and DC distribution systems[1]-[17]. Generally, the output voltages of the PV cells and FC cells are low, which need to be stepped up to higher levels by high stepup DC/DC converters for meeting the requirement of potential application. Fig. 1 shows a typical renewable energy system.

Manuscript received July 15, 2019; revised September 4, 2019; accepted September 12, 2019. Date of publication December 30, 2019; date of current version November 19, 2019. This work was supported by the National Natural Science Foundation (51577002), Top-Notch Personnel Foundation of the Anhui Higher Education Institutions of China (gxbjZD13). This paper was presented in part at the 2019 IEEE 10th International Symposium on Power Electronics for Distributed Generation Systems (PEDG), Xi'an, China, June 2019.

X. Liu, X. Hu, H. Chen, L. Chen, and Y. Zhang are with Anhui Key Laboratory of Power Electronics and Motion Control Technology, the College of Electrical and Electronic Engineering, Anhui University of Technology, Ma'anshan, China (e-mail: hxu-123@163.com).

X. Zhang is with the China University of Mining and Technology, Xuzhou, China (e-mail: zhangxiao@cumt.edu.cn).

Digital Object Identifier 10.24295/CPSSTPEA.2019.00028

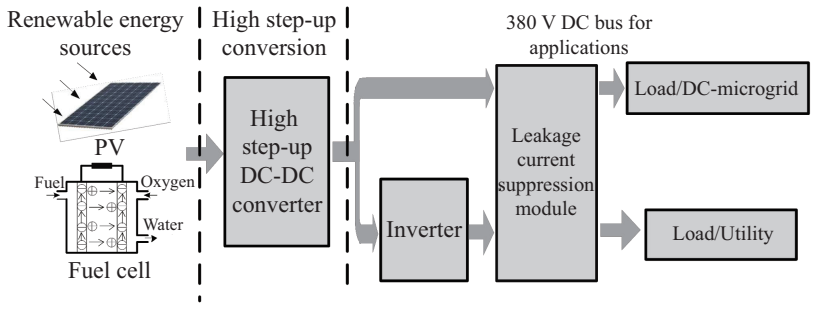

Fig. 1. Typical renewable energy system.

Generally, in some isolated converters such as flyback, halfbridge and full-bridge converters, the high voltage gain can be achieved by increasing turns ratio of the isolated transformer and the duty cycle of active switches. However, this method for high voltage gain will result in disadvantages of high voltage/current stress of power switches, large weight and size, and low efficiency [6]-[9]. So, non-isolated structures are recommended where isolation is not necessary. The traditional boost converter can achieve high voltage gain by increasing the duty cycle of the main switch. In fact, an extremely duty cycle will lead to the reverse recovery of output diode, electro magnetic interference(EMI), large current ripple and low efficiency. Switched-capacitor technology is applied in some converters to achieve high conversion ratio [10]-[13]. However, the switched-capacitor circuit often requires lots of active switches, and the active switches will also suffer instantaneous large current, increasing conduction loss. In the references [14]-[16], the switched-inductor technology has been combined with basic boost converters for obtaining the high voltage gain, but the voltage value across the power switch is still high, causing serious conduction losses. At the same time, the input current ripples are also large, which affects the lifetime of input dc sources.

The basic interleaved boost has advantages of low input current ripple, compact magnetic elements, and high power handling capability. However, the voltage gain of the conventional interleaved boost converter is only determined by the duty ratio. In practical application, the voltage gain is limited to five times due to the influence of parasitic parameters of some components. Some high gain interleaved boost converters were successfully developed by combining the coupled inductors with switched capacitors for renewable energy power system [1]-[7], [15]-[25].

In this paper, a novel interleaved boost converter with high step-up is proposed, in which the primary sides of coupled inductors are connected in parallel and the secondary sides of 


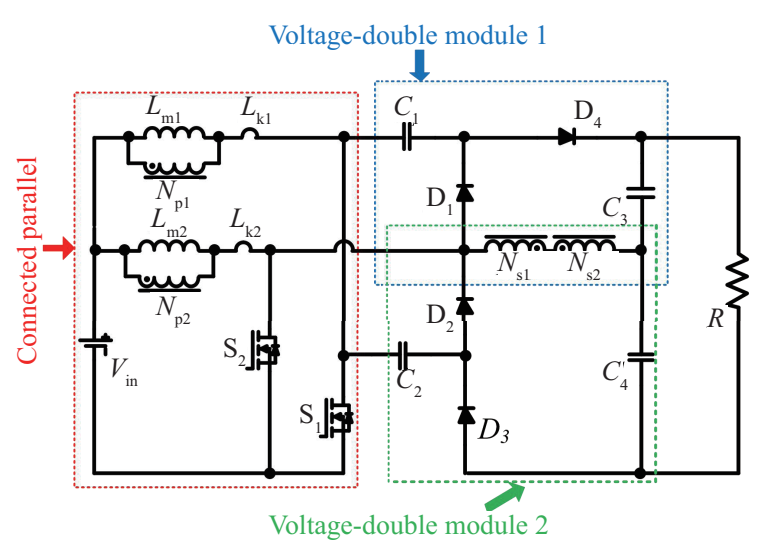

Fig. 2. The topology of the proposed converter.

coupled inductors are connected in series . In addition, voltage multiplier techniques that integrate coupled inductor and diode-capacitor are also used for higher voltage gain and lower voltage stress on power devices. The topology of the proposed converter is shown in Fig. 2.

\section{Operating Principles of Proposed Converter}

To simplify the circuit analysis, the assumptions are made as follows:

(a) All the power semiconductors and energy storage components are ideal, which means the on-state resistances of power semiconductors, the forward voltage drop of the diodes, and the equivalent series resistances (ESRs) of the inductors and capacitors are ignored.

(b) All the capacitances are large enough, and each capacitor voltage can be treated as constant.

(c) The relationship between $d_{1}$ and $d_{2}$ can be written as $d_{1}=d_{2}=d$, where $d_{1}$ and $d_{2}$ are the duty cycles of $\mathrm{S}_{1}$ and $\mathrm{S}_{2}$ respectively.

(d) The phase difference between the gate driving signals of $\mathrm{S}_{1}$ and $\mathrm{S}_{2}$ is $180^{\circ}$, and the operating duty cycle is not be lower than 0.5 .

In a switching cycle, when there is always current flowing through $L_{\mathrm{m} 1}$ and $L_{\mathrm{m} 2}$, the proposed converter operates in the continuous conduction mode (CCM), and when the current flowing through $L_{\mathrm{m} 1}$ and $L_{\mathrm{m} 2}$ is zero for a period of time, the proposed converter operates in discontinuous conduction mode (DCM).

According to the operation of $\mathrm{S}_{1}$ and $\mathrm{S}_{2}$, when the proposed converter operates in CCM, there are eight operated modes. Fig. 3 represents several key theoretical waveforms during a switching period. And Fig. 4 represents the equivalent circuits of the converter in different modes.

Mode I $\left[t_{0} \sim t_{1}\right]$ At the time of $t_{0}$, the main switch $S_{1}$ is switched on, the switch $\mathrm{S}_{2}$ maintains the state of conducting. The equivalent circuit is shown in Fig. 4(a). Because the current of the inductor can't be changed suddenly, the diode $\mathrm{D}_{4}$ is still on. The current through the diode $\mathrm{D}_{4}$ decreases gradually. When the current $i_{\mathrm{D} 4}$ is reduced to zero, the diode $\mathrm{D}_{4}$

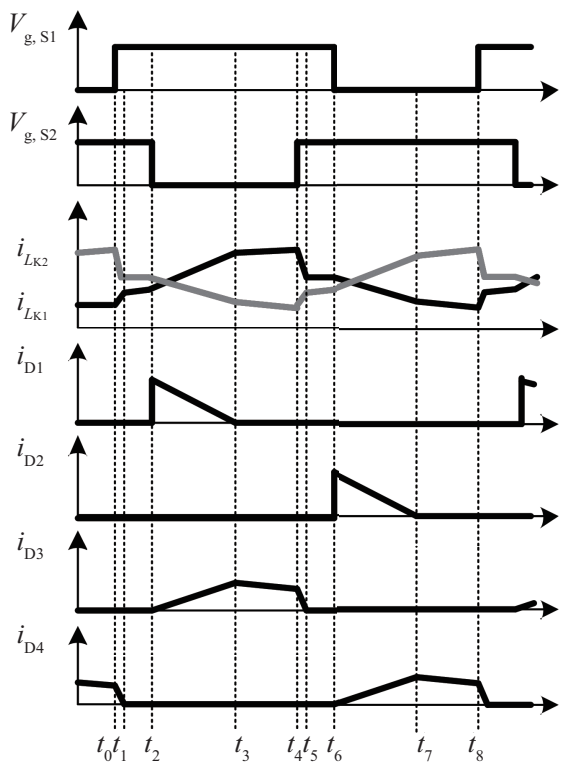

Fig. 3. Key waveforms of one cycle at CCM operation.

is turned off under ZCS condition, and this mode ends.

Mode II $\left[t_{1} \sim t_{2}\right]$ At the time of $t_{1}$, the main switches $S_{1}$ and $S_{2}$ are switched on. All diodes are reverse biased. The equivalent circuit is shown in Fig. 4(b). During this transition, $L_{\mathrm{m} 1}, L_{\mathrm{m} 2}, L_{\mathrm{k} 1}$ and $L_{\mathrm{k} 2}$ are charged linearly by input power. The energy of load is provided by the two output capacitors.

Mode III $\left[t_{2} \sim t_{3}\right]$ At the time of $t_{2}$, the main switch $\mathrm{S}_{2}$ is switched off, the switch $\mathrm{S}_{1}$ maintains the state of conducting. Diodes $\mathrm{D}_{1}$ and $\mathrm{D}_{3}$ are on, and the equivalent circuit is shown in Fig. 4(c).Part of energy stored in $L_{\mathrm{k} 2}$ is transferred to $C_{1}$ via $\mathrm{D}_{1}$. The voltage stress of switch is clamped to $V_{C l}$. The input voltage, coupled inductors and $V_{C 2}$ are in series connection to charge the output capacitor $C_{4}$, extending the voltage gain of this converter. The current $i_{L_{\mathrm{K} 2}}$ begins to decrease. At the same time, the current $i_{\mathrm{D}_{1}}$ is decreased gradually. $\mathrm{D}_{1}$ is turned off under ZCS condition, and this mode ends.

Mode IV $\left[t_{3} \sim t_{4}\right]$ At the time of $t_{3}, \mathrm{D}_{1}$ is turned off, as shown in Fig. $4(\mathrm{~d}) . L_{\mathrm{m} 1}$ and $L_{\mathrm{k} 1}$ are charged linearly by the input dc source. $C_{4}$ is still charged through $L_{\mathrm{m} 2}, L_{\mathrm{k} 2}$ and $C_{2}$. The load current is provided by $C_{3}$.

Mode $\mathrm{V}\left[t_{4} \sim t_{5}\right]$ At the time of $t_{4}$, the main switch $\mathrm{S}_{2}$ is switched on and the switch $\mathrm{S}_{1}$ maintains the on-state. The equivalent circuit is shown in Fig. 4(e). Because the current of the inductor can't be changed suddenly, the diode $\mathrm{D}_{3}$ is still on. When the current $i_{\mathrm{D} 3}$ of diode $\mathrm{D}_{3}$ is reduced to zero, the diode $\mathrm{D}_{3}$ is turned off under ZCS condition, and this mode ends.

Mode VI $\left[t_{5} \sim t_{6}\right]$ At the time of $t_{5}$, all diodes are switched off, the equivalent circuit shows in Fig. 4(f). In this mode, the main switches $S_{1}$ and $S_{2}$ are switched on. The energy of load is provided by the capacitors $C_{3}$ and $C_{4}$.

Mode VII $\left[t_{6} \sim t_{7}\right]$ At the time of $t_{6}$, the main switch $\mathrm{S}_{1}$ is switched off and the main switch $\mathrm{S}_{2}$ continues to be turned on. The diodes $\mathrm{D}_{2}$ and $\mathrm{D}_{4}$ are turned on. The equivalent circuit is shown in Fig. 4(g). Part of energy stored in $L_{\mathrm{k} 1}$ is transferred 


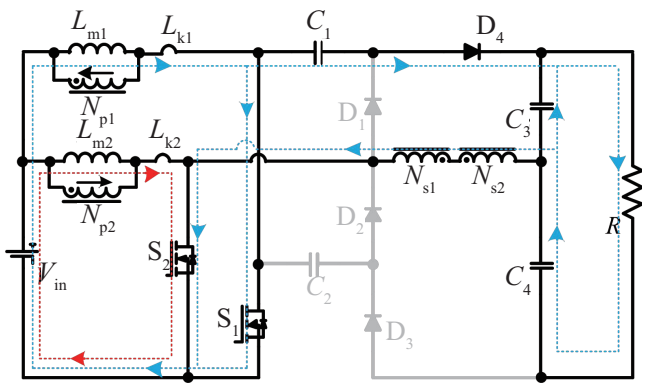

(a)

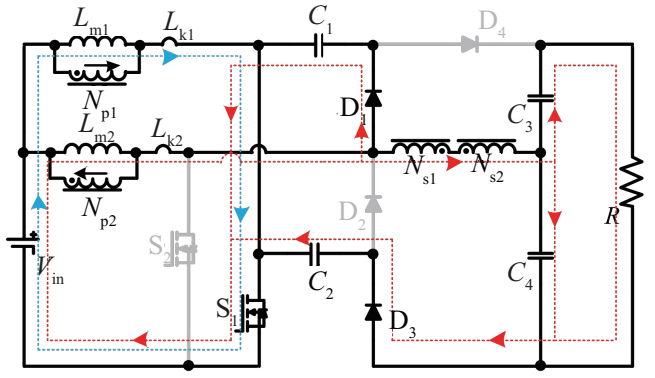

(c)

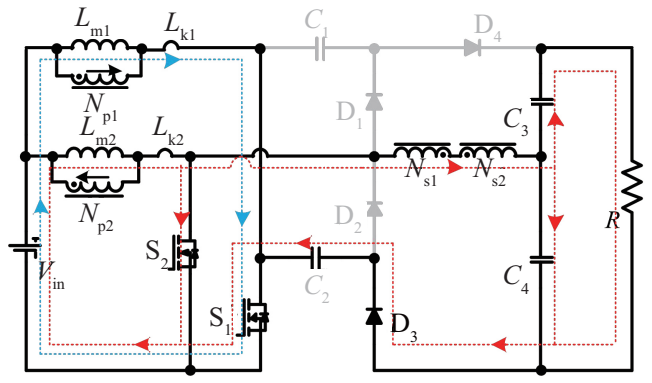

(e)

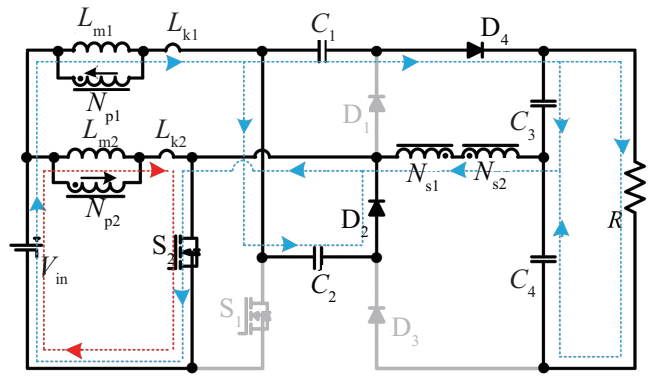

(g)

Fig. 4. Equivalent circuits of the proposed converter in different modes.

to $C_{2}$ via $\mathrm{D}_{2}$. The leakage inductor energy is reclaimed by $C_{2}$, which can be used to improve the efficiency of the converter. Another part of the energy stored in $L_{\mathrm{k} 1}$ and the energy stored in $C_{1}$ are transferred to $C_{3}$ via $\mathrm{D}_{4}$. The current $i_{L_{\mathrm{k} 1}}$ begins to decrease. At the same time, the current $i_{\mathrm{D}_{2}}$ is decreased gradually. The current of $\mathrm{D}_{2}$ drops to zero and it is turned off under ZCS condition, and this mode ends.

Mode VIII $\left[t_{7} \sim t_{8}\right]$ At the time of $t_{7}, \mathrm{D}_{2}$ is turned off, the equivalent circuit shows in Fig. 4(h). In this mode, $L_{\mathrm{m} 2}$ and $L_{\mathrm{k} 2}$ are charged linearly by the input voltage. $C_{3}$ is charged by $L_{\mathrm{m} 1}$, $L_{\mathrm{k} 1}$, and $C_{1}$. The load current is provided by $C_{4}$.

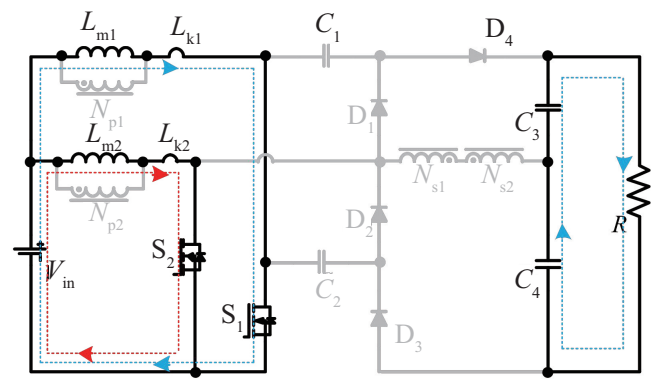

(b)

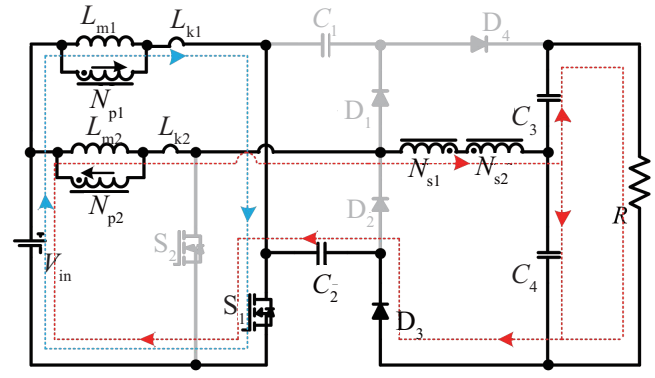

(d)

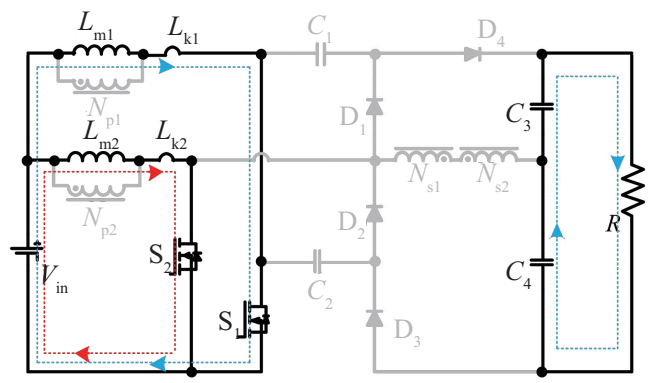

(f)

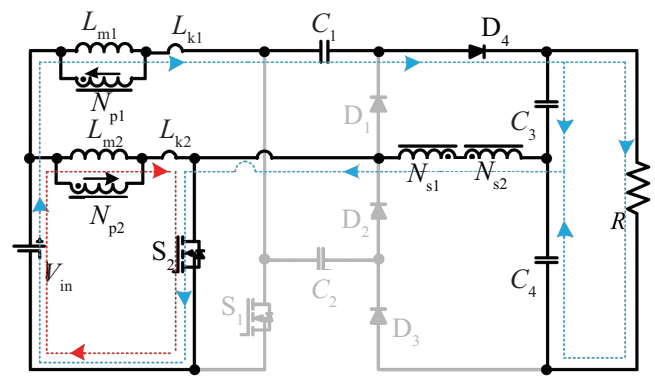

(h)

\section{Steady-State Analysis}

The characteristics of the proposed converter in CCM operation are analyzed in this section.

\section{A. Voltage Gain}

The voltage gain can be obtained by applying the voltsecond balance principle of the boost inductor in a switching cycle.

When the switch $\mathrm{S}_{1}$ is turned on

$$
V_{L_{\mathrm{ml}}}^{\mathrm{c}} \times T_{1_{\mathrm{on}}}=V_{L_{\mathrm{ml}}}^{\mathrm{disc}} \times T_{1_{\text {off }}},
$$


where the $T_{1 \text { on }}$ is the conducting time in one cycle $\mathrm{S}_{1}$ and the $T_{\text {loff }}$ is the turn-off time in one cycle. The $V_{L_{\mathrm{m} 1}}^{\mathrm{c}}$ is the charging voltage of $L_{\mathrm{m} 1}$ and $V_{L_{\mathrm{m} 1}}^{\text {disc }}$ is the discharging voltage of $L_{\mathrm{m} 1}$.

In order to simplify the steady-state analysis, the leakage inductance voltage is neglected. From mode II to mode VI, the voltage of the $L_{\mathrm{m} 1}$ as in the following equation:

$$
V_{L_{\mathrm{m} 1}}^{\mathrm{c}}=V_{\mathrm{in}} \text {. }
$$

By (1) and (2), the voltage of the $L_{\mathrm{m} 1}$ is

$$
V_{L_{\mathrm{ml}}}^{\mathrm{disc}}=\frac{T_{1 \mathrm{on}}}{T_{1 \text { off }}} V_{L_{\mathrm{ml}}}^{c}=\frac{d_{1}}{1-d_{1}} V_{L_{\mathrm{ml}}}^{\mathrm{c}}=\frac{d_{1}}{1-d_{1}} V_{\mathrm{in}} .
$$

where $d_{1}$ is the duty cycle of switch $\mathrm{S}_{1}$.

According to the same principle, when the switch $\mathrm{S}_{2}$ is opened, the voltage of $L_{\mathrm{m} 2}$ can be obtained as in the following equation:

$$
V_{L_{\mathrm{m} 2}}^{\text {disc }}=\frac{T_{2 \text { on }}}{T_{2 \text { off }}} V_{L_{\mathrm{m} 2}}^{\mathrm{c}}=\frac{d_{2}}{1-d_{2}} V_{L_{\mathrm{m} 2}}^{\mathrm{c}}=\frac{d_{2}}{1-d_{2}} V_{\mathrm{in}} .
$$

The $V_{L_{\mathrm{m} 2}}^{\mathrm{c}}$ is the charging voltage of $L_{\mathrm{m} 2}$ and $V_{L_{\mathrm{m} 2}}^{\text {disc }}$ is the discharging voltage of $L_{\mathrm{m} 2}$.

Where the $T_{2 \text { on }}$ is the conducting time in one cycle for $\mathrm{S}_{2}$ and the $T_{2 \text { off }}$ is the turn-off time in one cycle.

By the mode III, the voltage of the capacitor $C_{1}$ can be obtained as in the following equation:

$$
V_{C 1}=V_{\text {in }}+V_{L_{\mathrm{m} 2}}^{\mathrm{disc}}=V_{\text {in }}+\frac{d_{2}}{1-d_{2}} V_{\text {in }}=\frac{1}{1-d_{2}} V_{\text {in }} \text {. }
$$

Similarly, the expression of the voltage of the capacitor $C_{2}$ can be obtained by the mode VII,

$$
V_{C 2}=V_{\text {in }}+V_{L_{\mathrm{m} 1}}^{\text {disc }}=V_{\text {in }}+\frac{d_{1}}{1-d_{1}} V_{\text {in }}=\frac{1}{1-d_{1}} V_{\text {in }} .
$$

By mode VIII, the expression of the voltage of the capacitor $C_{3}$ can be obtained

$$
\begin{aligned}
V_{C 3} & =V_{\text {in }}+V_{L_{\mathrm{m} 1}}^{\text {disc }}+V_{C 1}+V_{N_{\mathrm{s} 1}}^{\text {disc }}+V_{N_{\mathrm{s} 2}}^{\mathrm{c}} \\
& =V_{\text {in }}+V_{L_{\mathrm{m} 1}}^{\text {disc }}+V_{C 1}+n k V_{L_{\mathrm{m} 1}}^{\text {disc }}+n k V_{L_{\mathrm{m} 2}}^{\mathrm{c}},
\end{aligned}
$$

where $n$ is the turn ratio, and $k$ is the coupling coefficient of coupled inductor. The $V_{N_{\mathrm{s} 1}}^{\text {disc }}$ is the discharging voltage of $N_{\mathrm{s} 1}$ and $V_{N_{\mathrm{s} 2}}^{\mathrm{c}}$ is the charging voltage of $N_{\mathrm{s} 2}$.

In the same way, the expression of the voltage of the capacitor $C_{4}$ can be obtained.

$$
\begin{aligned}
V_{C 4} & =V_{\mathrm{in}}+V_{L_{\mathrm{m} 2}}^{\mathrm{disc}}+V_{C 2}+V_{N_{\mathrm{s} 1}^{\mathrm{c}}}^{\mathrm{c}}+V_{N_{\mathrm{s} 2}^{\mathrm{disc}}}^{\mathrm{disc}} \\
& =V_{\mathrm{in}}+V_{L_{\mathrm{m} 2}}^{\mathrm{d}}+V_{C 2}+n k V_{L_{\mathrm{m} 1}}^{\mathrm{c}}+n k V_{L_{\mathrm{m} 2}}^{\mathrm{disc}}
\end{aligned}
$$

Where the $V_{N_{\mathrm{s} 1}}^{\mathrm{c}}$ is the charging voltage of $N_{\mathrm{s} 1}$ and $V_{N_{\mathrm{s} 2}}^{\text {disc }}$ is the discharging voltage of $N_{\mathrm{s} 2}$.

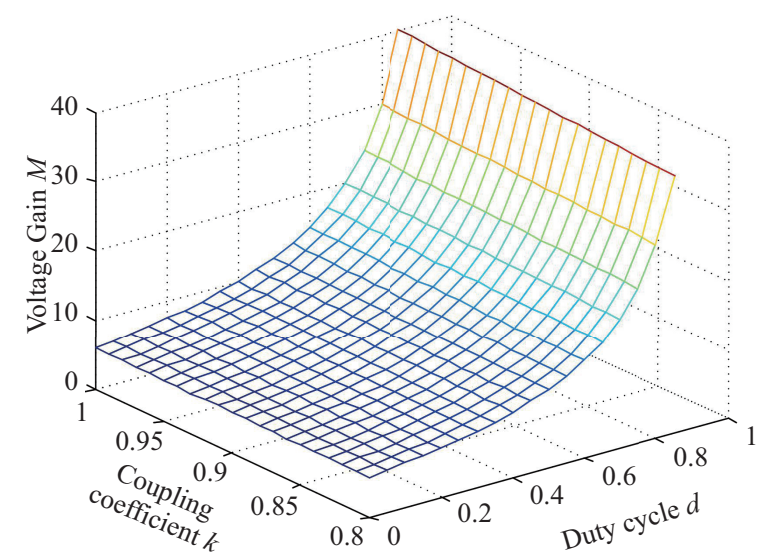

Fig. 5. The relationship between voltage gain, coupled coefficient and duty cycle.

Order $d_{1}=d_{2}=d$,

$$
V_{C 3}=V_{C 4}=\frac{2+n k}{1-d} V_{\text {in }} .
$$

According to mode II and mode VI, the expression of the output voltage can be obtained as in the following equations:

$$
V_{0}=V_{C 3}+V_{C 4}=\frac{4+2 n k}{1-d} V_{\text {in }} .
$$

Therefore, the voltage gain is attained as follow

$$
M=\frac{V_{0}}{V_{\text {in }}}=\frac{4+2 n k}{1-d} .
$$

Fig. 5 shows the relationship between voltage gain, the coupling coefficient, and duty cycle. According to this diagram, it can be seen that the coupled coefficient of the coupling inductor has little effect on the voltage gain. Therefore, in order to simplify the calculation, the coupled coefficient $k=1$ can be assumed in the theoretical analysis.

\section{B. Voltage Stress of the Semiconductor Devices}

In this section, the steady-state analysis of the proposed converter is given. It is assumed that the coupled coefficient $k$ is 1 . Based on the operational principle and the results of equals (5)-(11), the voltage stress on the switches $S_{1}, S_{2}$ and diodes $\mathrm{D}_{1} \sim \mathrm{D}_{4}$ are derived as

$$
\begin{aligned}
& V_{\mathrm{S} 1}=V_{\mathrm{S} 2}=\frac{1}{1-d} V_{\mathrm{in}}=\frac{1}{4+2 n} V_{0} \\
& V_{\mathrm{D} 1}=V_{\mathrm{D} 2}=\frac{2}{1-d} V_{\mathrm{in}}=\frac{2}{4+2 n} V_{0} \\
& V_{\mathrm{D} 3}=V_{\mathrm{D} 4}=\frac{2+2 n}{1-d} V_{\mathrm{in}}=\frac{2+2 n}{4+2 n} V_{0}
\end{aligned}
$$

The plot of the normalized diode and switch voltage stress 


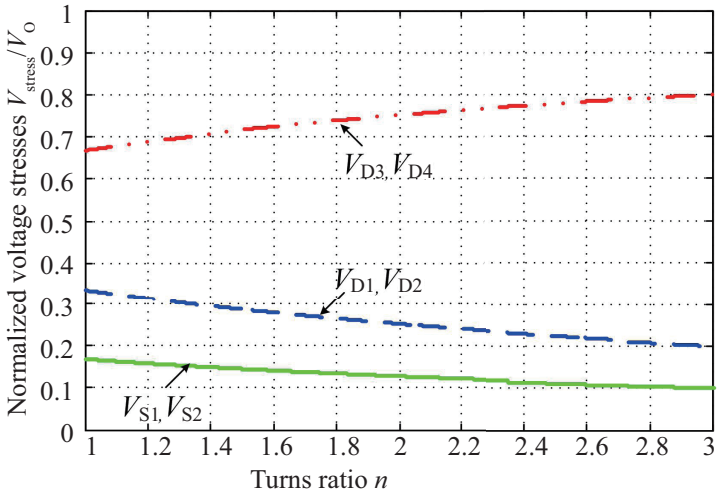

Fig. 6. Normalized power components voltage stress.

with the turns ratio of the coupled inductors is shown in Fig. 6. It can be seen that the voltage stress of diode and main switches is always lower than the output voltage. The voltage stress of switches is no more than two-tenth of output voltage. So the lower voltage rating MOSFETs and diodes can be selected to reduce both switching and conduction losses in high step-up and high output voltage application.

\section{Voltage Sharing of Two Branch Output}

Assuming that the duty cycle of the main switch $\mathrm{S}_{1}$ is $d_{1}$, the duty cycle of the main switch $\mathrm{S}_{2}$ is $d_{2}$ and $d_{1} \neq d_{2}$. In addition, the power MOSFET and diode usually have some voltage drops (assumed as $V_{\mathrm{d}}$ ) which should be considered in practical circuit design. By applying the volt-second balance to the magnetizing inductance, the voltage difference between the two output capacitors $C_{3}$ and $C_{4}$ is

$$
V_{C 3}-V_{C 4}=\frac{n\left(d_{1}-d_{2}\right)}{\left(1-d_{1}\right)\left(1-d_{2}\right)}\left(V_{\text {in }}-V_{\mathrm{d}}\right) \neq 0
$$

It can be seen from (15), there is a voltage difference between the capacitor $C_{3}$ and $C_{4}$ when the duty cycle $d_{1}$ is not equal to $d_{2}$. Although it may be small, it still results in unbalanced of the voltage on the $C_{3}$ and $C_{4}$. To alleviate the above problem of the proposed converter, a voltage-current loop together with a simple voltage-balance loop is presented in Fig. 7.

The voltage-balance loop aims to reduce the voltage difference between $C_{3}$ and $C_{4}$. In this loop, the different duty cycle $\Delta d$ is achieved by a simple PI controller through the $\Delta V$ between $C_{3}$ and $C_{4}$. Then the duty cycle $d_{1}$ of the switch $\mathrm{S}_{1}$ can be easily obtained by

$$
d_{1}=d_{2}-\Delta d
$$

By only controlling one of the boost converters, the input current and output voltage of the converter can be easily controlled to be stable. In Fig. 6, the blue block is a voltage balance loop that aims to reduce the unbalance voltage between

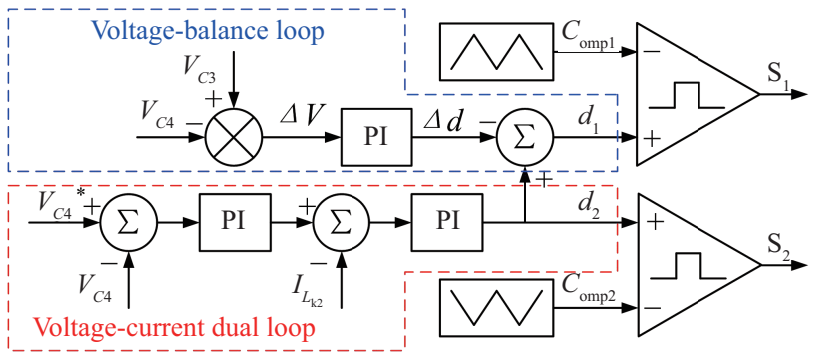

Fig. 7. Loop control of the proposed converter.

$C_{3}$ and $C_{4}$. The red block is the voltage-current dual loop that aims to ensure the stability of the input current and output voltage.

From (16), the voltage-balance process is: when the voltage of $C_{3}$ is higher than $C_{4}$, the different duty $\Delta d$ is positive which makes the $d_{1}$ decrease. Then the voltage of $C_{3}$ comes to decrease to follow $V_{C 4}$. Conversely, $V_{C 3}$ will increase to $V_{C 4}$.

\section{Analysis of Input Current Ripple Under CCM Mode}

In order to simplify the analysis, the influence of transient mode can be ignored, the leakage current is equivalent to linear variation as shown in Fig. 8(a), at the time of $t_{1}$, the leakage inductance current and the input current can be expressed as

$$
\begin{gathered}
i_{L_{\mathrm{k} 1}}\left(t_{1}\right)=I_{L_{\mathrm{k} 1}, \mathrm{avg}}-\frac{(1-d) \Delta i_{L_{\mathrm{k} 1}}}{2 d} \\
=\frac{(2+n k) I_{\mathrm{O}}}{1-d}-\frac{V_{\mathrm{in}}(1-d) T_{\mathrm{S}}}{2 L_{\mathrm{m} 1}} \\
i_{L_{\mathrm{k} 2}}\left(t_{1}\right)=I_{L_{\mathrm{k} 2}, \mathrm{avg}}+\frac{\Delta i_{L_{\mathrm{k} 2}}}{2}=\frac{(2+n k) I_{0}}{1-d}+\frac{V_{\mathrm{in}} d T_{\mathrm{S}}}{2 L_{\mathrm{m} 2}} \\
i_{\mathrm{in}}\left(t_{1}\right)=i_{L_{\mathrm{k} 1}}\left(t_{1}\right)+i_{L_{\mathrm{k} 2}}\left(t_{1}\right) \\
=\frac{(4+2 n k) I_{0}}{1-d}+\left(\frac{d}{2 L_{\mathrm{m} 2}}-\frac{1-d}{2 L_{\mathrm{m} 1}}\right) V_{\mathrm{in}} T_{\mathrm{S}} .
\end{gathered}
$$

The expression of the input current ripple obtained as

$$
\Delta i_{\text {in }}=\left|\left(\frac{d}{2 L_{\mathrm{m} 2}}-\frac{1-d}{2 L_{\mathrm{m} 1}}\right)\right| V_{\mathrm{in}} T_{\mathrm{s}}
$$

Assuming $L_{\mathrm{m} 2}=N L_{\mathrm{m} 1}$,

$$
\Delta i_{\text {in }}=\left|\frac{(N+1) d}{N}-1\right| \frac{V_{\text {in }} T_{\mathrm{S}}}{2 L_{\mathrm{m} 1}} .
$$

The relation between the input current ripple and the duty cycle $d$ is given in Fig. 8. It can be seen from Fig. 8(b) that the inductance value of the converter can be designed according to the duty cycle of the converter, and the zero ripples of the input current can be realized theoretically.

\section{E. Performance Comparison}

The performance of comparison among interleaved high step-up converters published in [20], [21], [25] and the 

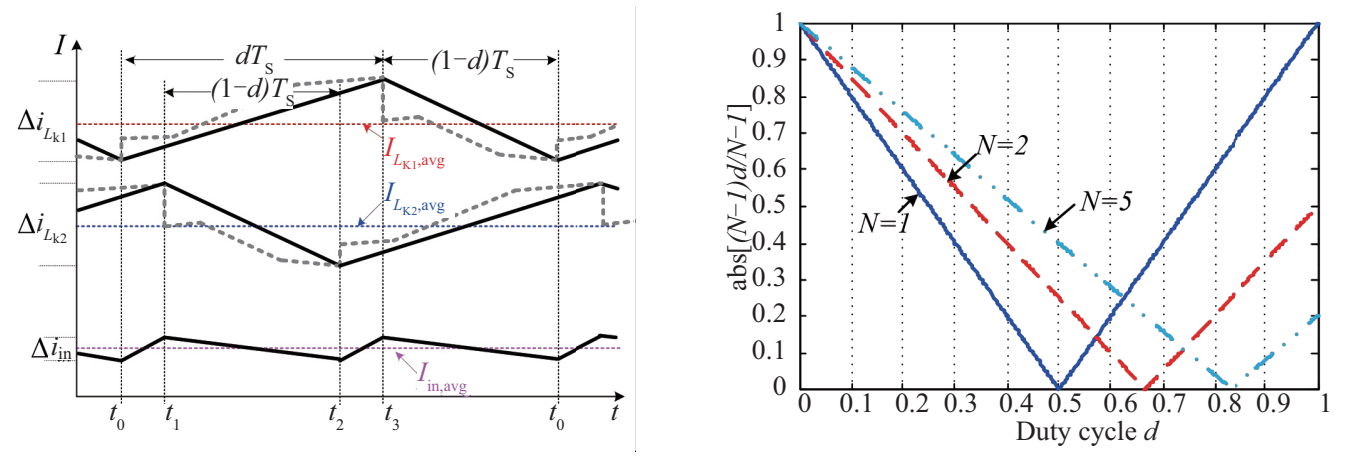

Fig. 8. Diagram of input current ripple analysis. (a) Current analysis. (b) Relation between current ripple and duty cycle.

TABLE I

Performance Comparison in Different Converters

\begin{tabular}{lcccc}
\hline \hline \multicolumn{1}{c}{ Topology } & $\begin{array}{c}\text { Converter in } \\
{[20]}\end{array}$ & $\begin{array}{c}\text { Converter in } \\
{[25]}\end{array}$ & Converter in [21] & $\begin{array}{c}\text { Proposed } \\
\text { converter }\end{array}$ \\
\hline Numbers of active switches & 2 & 2 & 2 & 2 \\
Numbers of diodes & 6 & 8 & 4 & 4 \\
Number of capacitors & 5 & 5 & 3 & 4 \\
Number of windings & 6 & 6 & 5 & 4 \\
Voltage gain & $\frac{2+2 n k}{1-d}$ & $\frac{1+3 n k}{1-d}$ & $\frac{2+n k}{1-d}$ & $\frac{4+2 n k}{1-d}$ \\
Voltage stress of active & $\frac{1}{2+2 n k} V_{\mathrm{O}}$ & $\frac{1}{1+3 n k} V_{\mathrm{O}}$ & $\frac{1}{2+n k} V_{\mathrm{O}}$ & $\frac{1}{4+2 n k} V_{\mathrm{O}}$ \\
switches & $\frac{1+2 n k}{2+2 n k} V_{\mathrm{O}}$ & $\frac{1+2 n k}{1+3 n k} V_{\mathrm{O}}$ & $V_{\mathrm{O}}$ & $\frac{2+2 n k}{4+2 n k} V_{\mathrm{O}}$ \\
The maximum voltage stress \\
on diodes
\end{tabular}

proposed converter is shown in Table I. One can see that the proposed converter is higher than those of the other topologies and the voltage stress on switches is lower than those of the other. In addition, the number of windings are also minimal in these converters. It is favorable in terms of reliability, circuit volume, and cost. Therefore, the proposed converter is a good alternative for applications that require ultra-step-up voltage gain with high efficiency.

The Fig. 9 clearly shows the value of the voltage stress of each converter under different turns ratio. Comparing with the literatures[20], [21] and [25], the proposed converter has the lower voltage stress on switches and diodes. So switches with lower voltage rating and diodes with lower forward voltage drop can be adapted, reducing the on-state losses.

\section{F. Analysis of Losses}

In order to analyze the loss of the converter, the parasitic parameters of the converter are assumed as follows.

$V_{\mathrm{FS}}$ and $r_{\mathrm{S}}$ are forward voltage drop and on-resistance of the switches when the main switches are turned on. $V_{\mathrm{FD}}$ and $r_{\mathrm{D}}$ are forward voltage drop and on-resistance of the diodes when the diodes are turned on. The parasitic resistance of coupled inductor and capacitor are $r_{L}$ and $r_{C}$ respectively.

The conduction losses equations about the power switches and diodes are as follow:

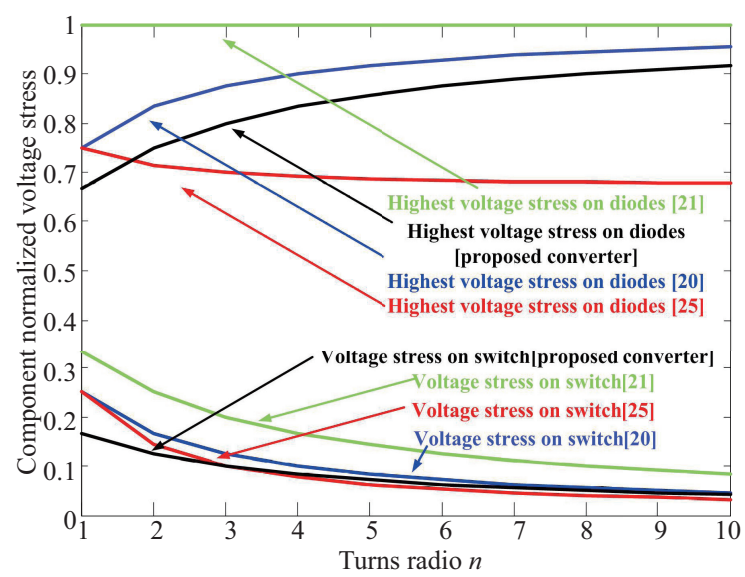

Fig. 9. Comparison of components normalized voltage stress between proposed converter and other converters in the literatures.

$$
\begin{aligned}
P_{\text {cond }, i i} & =\frac{1}{T_{\mathrm{S}}} \int_{0}^{d T_{\mathrm{S}}}\left(V_{\mathrm{FS} i} i_{\mathrm{S} i}+r_{\mathrm{S} i} i_{\mathrm{S} i}^{2}\right) \mathrm{d} t \\
& =\left(V_{\mathrm{FS} i}+r_{\mathrm{S} i} I_{\mathrm{S} i}\right) I_{\mathrm{S} i} d \\
P_{\text {cond, }, \mathrm{Dj}} & =\frac{1}{T_{\mathrm{S}}} \int_{d T_{\mathrm{s}}}^{T_{\mathrm{S}}}\left(V_{\mathrm{FD}} i_{\mathrm{D} j}+r_{\mathrm{D}} i_{\mathrm{Dj} j}^{2}\right) \mathrm{d} t \\
& =\left(V_{\mathrm{FD}}+r_{\mathrm{D}} I_{\mathrm{D} j}\right) I_{\mathrm{D} j}(1-d) .
\end{aligned}
$$


The average currents of the main switches $\mathrm{S}_{1}, \mathrm{~S}_{2}$ and $\mathrm{D}_{1} \sim \mathrm{D}_{4}$ $\operatorname{are} I_{\mathrm{S} 1} \cdot I_{\mathrm{S} 2} \cdot I_{\mathrm{D} 1} \sim I_{\mathrm{D} 4}$, respectively.

The switching loss equations about the power switches and diodes are as follows:

$$
\begin{aligned}
P_{\mathrm{SW}, \mathrm{S} 1} & =\frac{1}{T_{\mathrm{S}}} \int_{0}^{t_{\mathrm{on}}} V_{\mathrm{S} 1} i_{\mathrm{S} 1} \mathrm{~d} t+\int_{0}^{t_{\mathrm{off}}} V_{\mathrm{S} 1} i_{\mathrm{S} 1} \mathrm{~d} t \\
& =\frac{1}{6} f_{\mathrm{s}} V_{\mathrm{S} 1} \frac{I_{\mathrm{S} 1}}{d}\left(t_{\mathrm{on}}+t_{\mathrm{off}}\right) \\
P_{\mathrm{SW}, \mathrm{S} 2} & =\frac{1}{T_{\mathrm{S}}} \int_{0}^{t_{\mathrm{on}}} V_{\mathrm{S} 2} i_{\mathrm{S} 2} \mathrm{~d} t+\int_{0}^{t_{\mathrm{off}}} V_{\mathrm{S} 2} i_{\mathrm{S} 2} \mathrm{~d} t \\
& =\frac{1}{6} f_{\mathrm{s}} V_{\mathrm{S} 2} \frac{I_{\mathrm{S} 2}}{d}\left(t_{\mathrm{on}}+t_{\mathrm{off}}\right) \\
P_{\mathrm{SW}, \mathrm{D} 1} & =P_{\mathrm{SW}, \mathrm{D} 2}=\frac{1}{T_{\mathrm{S}}} \int_{0}^{t_{\mathrm{b}}} P_{D(t)} \mathrm{d} t \\
& =\frac{1}{6} f_{\mathrm{s}} V_{\mathrm{Doff}} I_{\mathrm{rr}} t_{\mathrm{b}}=\frac{1}{3} f_{\mathrm{s}} \frac{V_{\text {in }}}{1-D} I_{\mathrm{rr}} t_{\mathrm{b}} \\
P_{\mathrm{SW}, \mathrm{D} 3}= & P_{\mathrm{SW}, D 4}=\frac{1}{T_{\mathrm{S}}} \int_{0}^{t_{\mathrm{b}}} P_{D(t)} \mathrm{d} t \\
= & \frac{1}{6} f_{\mathrm{s}} V_{\mathrm{Doff}} I_{\mathrm{rr}} t_{\mathrm{b}}=\frac{1}{3} f_{\mathrm{s}} \frac{(1+n) V_{\mathrm{in}}}{1-D} I_{\mathrm{rr}} t_{\mathrm{b}} .
\end{aligned}
$$

The total loss of the main switches is as follows:

$$
P_{\mathrm{S}, \mathrm{Loss}}=P_{\text {cond }, \mathrm{S} 1}+P_{\text {cond, }, 22}+P_{\mathrm{SW}, \mathrm{S} 1}+P_{\mathrm{SW}, \mathrm{S} 2} \text {. }
$$

The total loss of the diodes is:

$$
P_{\mathrm{D}, \mathrm{Loss}}=P_{\text {cond, D1 }}+\cdots+P_{\text {cond, D4 }}+P_{\mathrm{SW}, \mathrm{D} 1}+\cdots+P_{\mathrm{SW}, \mathrm{D4} 4} \cdot
$$

The power loss of the coupled inductors $T_{1}, T_{2}$ in the converter is:

$$
\begin{aligned}
& P_{\text {cond }, L_{\mathrm{m} 1}}=P_{\text {cond }, L_{\mathrm{m} 2}}=r_{L_{\mathrm{m} 1,2}} I_{L_{\mathrm{m} 1,2}^{2}}^{2} \\
& P_{\text {cond }, L_{\mathrm{s} 1}}=P_{\text {cond }, L_{\mathrm{s} 2}}=r_{L_{\mathrm{s} 1,2}} I_{L_{\mathrm{s} 1,2}^{2}}^{2}
\end{aligned}
$$

The total loss of the coupled inductor is:

$$
P_{\mathrm{T}, \mathrm{Loss}}=P_{\text {cond }, L_{\mathrm{m} 1}}+P_{\text {cond } L_{\mathrm{m} 2}}+P_{\text {cond }, L_{\mathrm{s} 1}}+P_{\text {cond }, L_{\mathrm{s} 2}}
$$

The power loss of the capacitor is:

$$
P_{\text {cond, }, C_{\mathrm{m}}}=\frac{1}{T_{\mathrm{S}}}\left(\int_{0}^{T_{\mathrm{c}}} r_{C_{\mathrm{m}}} i_{C_{\mathrm{m}-\mathrm{c}}}^{2} \mathrm{~d} t\right)+\frac{1}{T_{\mathrm{S}}}\left(\int_{0}^{T_{\text {dise }}} r_{C_{\mathrm{m}}} i_{C_{\mathrm{m} r \text { dice }}}^{2} \mathrm{~d} t\right),
$$

where $T_{\mathrm{c}}, T_{\text {disc, }}, i_{C_{\mathrm{m} \cdot \mathrm{c}}}$ and $i_{C_{\mathrm{m} \text {-dise }}}$ are the charging time, discharging time, charging current and discharging current of capacitors in a cycle respectively.

The total power of the capacitor loss is:

$$
P_{C, \mathrm{Loss}}=P_{\text {cond, }, 11}+P_{\text {cond }, C 2}+P_{\text {cond }, C 3}+P_{\text {cond, }, 4} \text {. }
$$

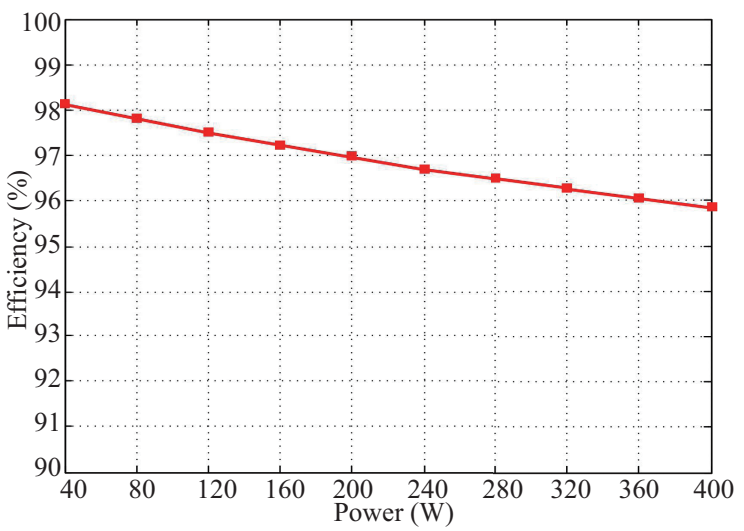

Fig. 10. The waveform of the theoretical efficiency.

In summary, the total power loss of the converter is:

$$
P_{\mathrm{L} \text { oss }}=P_{\mathrm{S}, \text { Loss }}+P_{\mathrm{D}, \mathrm{Loss}}+P_{T, \mathrm{Loss}}+P_{C, \mathrm{Loss}} .
$$

Therefore, the efficiency of the proposed converter when operating in CCM mode is:

$$
\eta=\frac{P_{0}}{P_{0}+P_{\text {Loss }}} \times 100 \%,
$$

where output power: $P_{\mathrm{O}}=V_{\mathrm{O}}^{2} / R$.

When $V_{\mathrm{in}}=25 \mathrm{~V}, n=1, d=0.6, V_{\mathrm{FS}}=0.8 \mathrm{~V}, V_{\mathrm{FD}}=0.8 \mathrm{~V}, r_{\mathrm{D}}$ $=1 \mathrm{~m} \Omega, r_{\mathrm{S}}=50 \mathrm{~m} \Omega, t_{\mathrm{on}}+t_{\text {off }}=72 \mathrm{~ns}, t_{\mathrm{b}}=35 \mathrm{~ns}, I_{\mathrm{rr}}=10 \mu \mathrm{A}, r_{L_{\mathrm{m}}}$ $=r_{L_{\mathrm{s}}}=50 \mathrm{~m} \Omega$ and $r_{C}=50 \mathrm{~m} \Omega$. Fig. 10 shows waveform of the theoretical efficiency.

\section{Design Considerations}

\section{A. Inductor Selection}

The design of the coupled inductors is based on the boundary operating condition of the magnetizing inductance. The turns ratio of the coupled inductors $n$ and the coupled coefficient $k$ are considered unity in the design procedure. Due to the circuit symmetry, the coupled inductors average current is identical, and the input current $I_{\mathrm{in}}$ is the summation of $I_{L_{\mathrm{m} 1}}$ and $I_{L_{\mathrm{m}}}$.

$$
\begin{gathered}
I_{L_{\mathrm{m} 1}}=I_{L_{\mathrm{m} 2}} \\
I_{\text {in }}=I_{L_{\mathrm{m} 1}}+I_{L_{\mathrm{m} 2}}
\end{gathered}
$$

Considering the ideal efficiency, the relation between $I_{\text {in }}$ and the output current $I_{\text {out }}$ could be achieved

$$
\begin{gathered}
P_{\text {in }}=P_{\text {out }} \\
I_{\text {in }} V_{\text {in }}=I_{\text {out }} V_{\text {out }},
\end{gathered}
$$

where $P_{\text {in }}$ and $P_{\text {out }}$ are the input and output power, respectively. By considering the voltage gain (11), and the input current (38) in (40), the relation between $I_{L_{\mathrm{ml}}}$ which is equal to $I_{L_{\mathrm{m}}}$, and $I_{\text {out }}$ is obtained 


$$
\begin{gathered}
I_{L_{\mathrm{m} 1}}=I_{L_{\mathrm{m} 2}}=\frac{2+n k}{1-d} I_{\text {out }} \\
V_{L_{\mathrm{m}}}=L_{\mathrm{m}} \frac{\Delta I_{L_{\mathrm{m}}}}{\Delta t} .
\end{gathered}
$$

So, according to the nominal output power, the magnetizing inductance average current and the desired current ripple $\Delta I_{L_{\mathrm{m}}}$ can be calculated from (41) and (42) on the basis of the CCM operation range.

When the switches are turned on, the voltage on the input magnetizing inductor is equal to $V_{\text {in }}$. Based on (42), $L_{\mathrm{m}}$ can be obtained as below:

$$
L_{\mathrm{m}}=\frac{V_{\text {in }} d}{f \Delta I_{L_{\mathrm{m}}}},
$$

in which $f$ is the switching frequency.

According to the required voltage gain , the equation of turns ratio can be expressed as:

$$
n=\frac{M_{\mathrm{CCM}}(1-D)-4}{2} .
$$

\section{B. Capacitors Selection}

The capacitor design mainly considers the voltage stress and the fluctuation of the voltage on the every capacitor to a certain range, and the capacitance value can be selected according to the formula (45).

$$
C_{1 \sim 4} \geqslant \frac{P_{C 1 \sim 4}}{2 V_{C 1 \sim 4} \Delta V_{C 1 \sim 4} f}
$$

In practical applications, with the increase of the capacitance, the equivalent series impedance of an aluminum electrolytic capacitor will become smaller. Therefore, the capacitance is always selected to be greater than the calculated result for the sake of reducing the power losses.

\section{EXPERIMENTAL RESULTS}

An experimental prototype circuit of the presented converter is built and tested in the laboratory in order to verify the validity of the theoretical analysis. The components of the converterare shown in Table II.

Fig. 11 (a) and (b) show the waveforms of currents of the leakage inductor $L_{\mathrm{k} 1}, L_{\mathrm{k} 2}$ and input current $i_{\mathrm{in}}$. The current $i_{L_{\mathrm{k} 1}}$ and $i_{L_{\mathrm{K} 2}}$ are nearly equal, and the input current ripple is lower than the currents of two input branches due to the interleaved operation. It helps to improve the efficiency of the input power supply.

Fig. 12 show the waveforms of currents of main switches $\mathrm{S}_{1}, \mathrm{~S}_{2}$ and diodes $\mathrm{D}_{1} \sim \mathrm{D}_{4}$. From the experimental waveform, the diodes $\mathrm{D}_{1}$ and $\mathrm{D}_{2}$ are turned off under the ZCS condition and the main switches $\mathrm{S}_{1}$ and $\mathrm{S}_{2}$ are turned on under the ZCS
TABLE II

Utilized Components and Parameters of the Prototype

\begin{tabular}{lc}
\hline \multicolumn{1}{c}{ Component } & Parameter \\
\hline Input voltage $V_{\text {in }}$ & $25 \sim 30 \mathrm{~V}$ \\
Output voltage $V_{\mathrm{O}}$ & $400 \mathrm{~V}$ \\
Maximum output power $P$ & $400 \mathrm{~W}$ \\
Switching frequency $f_{\mathrm{s}}$ & $40 \mathrm{kHz}$ \\
Inductor $L_{\mathrm{m} 1}, L_{\mathrm{m} 2}$ & $100 \mu \mathrm{H}$ \\
Power switch $\mathrm{S}_{1}, \mathrm{~S}_{2}$ & $\mathrm{IRFP} 260 \mathrm{~N}$ \\
Diode $\mathrm{D}_{1} \sim \mathrm{D}_{4}$ & $\mathrm{DSEI}-06 \mathrm{~A}$ \\
Capacitors $C_{1}$ and $C_{2}$ & $47 \mu \mathrm{F} / 100 \mathrm{~V}$ \\
Capacitor $C_{3}$ and $C_{4}$ & $100 \mu \mathrm{F} / 250 \mathrm{~V}$ \\
\hline \hline
\end{tabular}

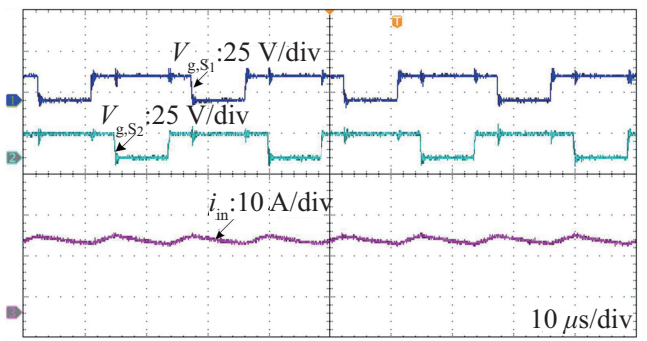

(a)

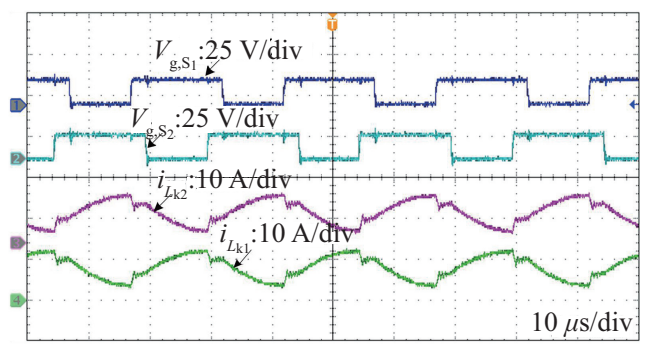

(b)

Fig. 11. Waveforms of $i_{L_{\mathrm{k} 1}}, i_{L_{\mathrm{k} 2}}$, and $i_{\mathrm{in}}$ : (a) $i_{\mathrm{in}}$. (b) $i_{L_{\mathrm{k} 1}}, i_{L_{\mathrm{k} 2}}$.

condition. Besides, the diodes $\mathrm{D}_{3}$ and $\mathrm{D}_{4}$ are switched on and switched off all under the ZCS condition. The switching losses of main switches and diodes are reduced effectively, and the efficiency of the proposed converter can be improved.

Fig. 13(a) and (b) shows that the voltage stress on the diodes $D_{1} \sim D_{4}$. The voltage stress of the diodes $D_{1}$ and $D_{2}$ are approximately $130 \mathrm{~V}$ and that of $\mathrm{D}_{3}$ and $\mathrm{D}_{4}$ are only $2 / 3$ of the output voltage. From Fig. 13(c), the voltage stress of main switches are about $67 \mathrm{~V}$, only 1/6 of the output voltage. So, the MOSFET with low on-resistance and low voltage level can be used to reduce the conduction losses and improve the efficiency of the converter. Fig. 13(d) shows the voltage of output capacitors. With the closed-loop control, the voltage of $C_{3}$ and $C_{4}$ are equal. It defends that the analysis of the voltage balance control is right.

Fig. 14 shows the dynamic response because of the variation of load. It can be seen that the output voltage is maintained at $400 \mathrm{~V}$ when the load changes suddenly. It proves that the converter has better dynamic performance and it is consistent with the previous small-signal analysis conclusion. 


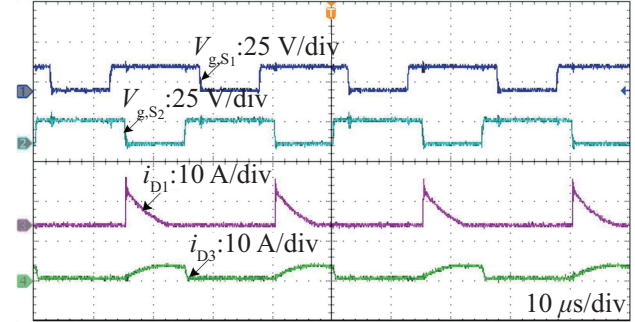

(a)

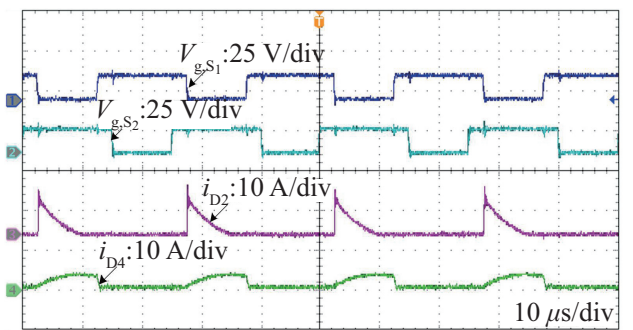

(b)

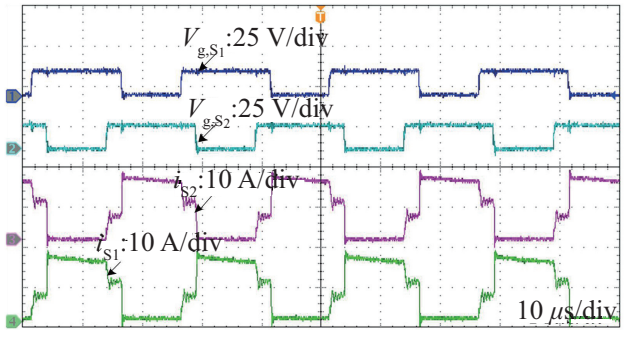

(c)

Fig. 12. Waveforms of currents of main switches and diodes. (a) $i_{\mathrm{D} 1}, i_{\mathrm{D} 3}$. (b) $i_{\mathrm{D} 2}$, $i_{\mathrm{D} 4 \cdot}(\mathrm{c}) i_{\mathrm{S} 1}, i_{\mathrm{S} 2}$.

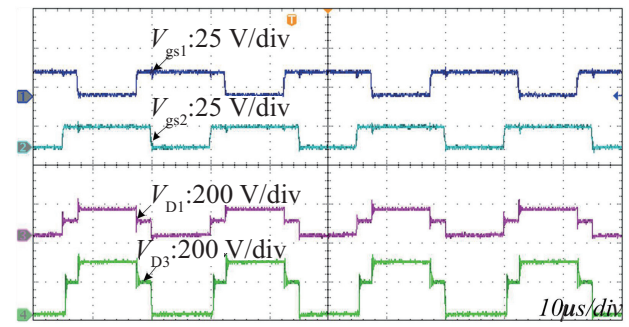

(a)

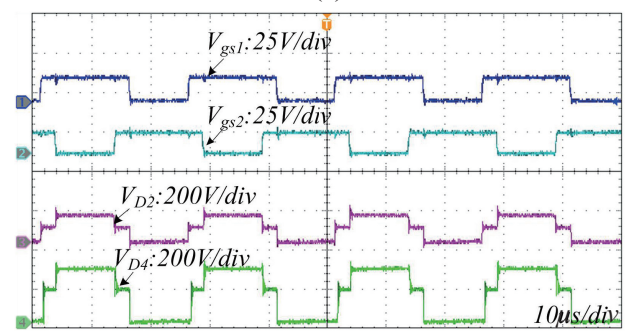

(b)

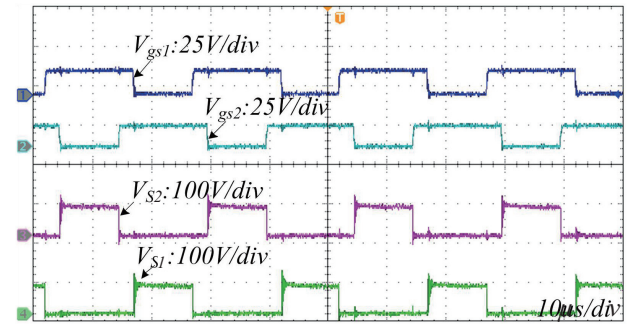

(c)

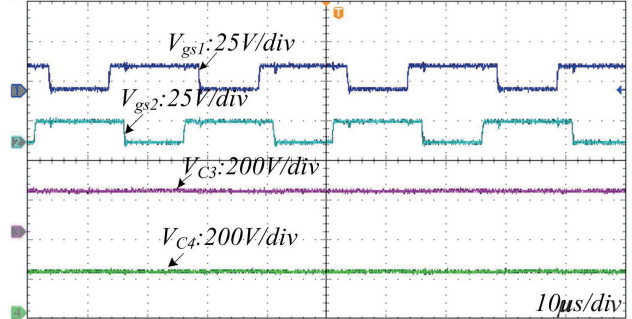

(d)

Fig. 13. Voltage stresses of main switches and diodes: (a) $V_{\mathrm{D} 1}, V_{\mathrm{D} 3}$. (b) $V_{\mathrm{D} 2}$, $V_{\mathrm{D} 4} \cdot(\mathrm{c}) V_{\mathrm{S} 1}, V_{\mathrm{S} 2}$ (d) $V_{C 3}, V_{C 4}$.

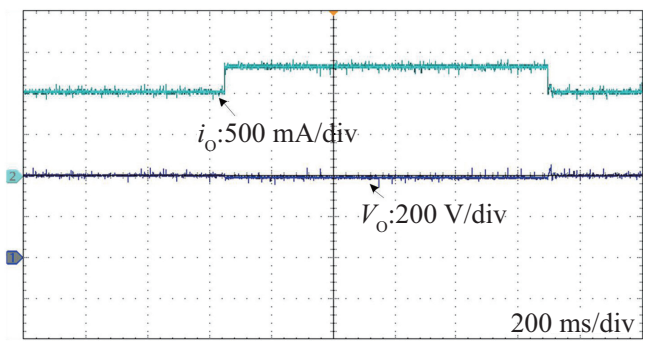

Fig. 14. The experimental waveform of the step load.

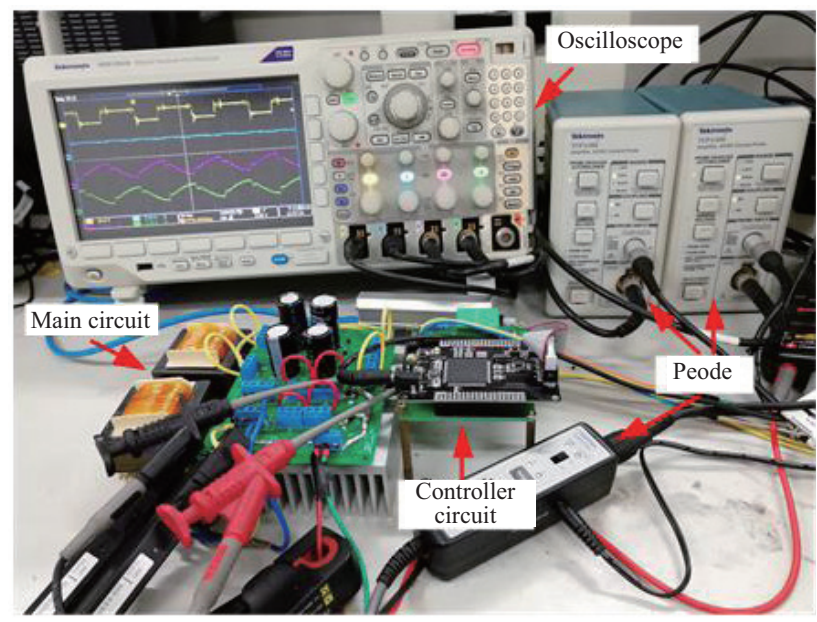

Fig. 15. The picture of experiment testing platform.

Fig. 15 shows the picture of the experimental platform, and some key components are marked. The efficiency curves at different input voltages are shown in Fig. 16. The conversion efficiency of proposed converter at full load can reach $93.2 \%$ even the input voltage is reduced to $20 \mathrm{~V}$. The maximum conversion efficiency of the converter is $95.0 \%$ when the output power is $280 \mathrm{~W}$ and input voltage is $30 \mathrm{~V}$.

\section{CONCLUSIONS}

This paper has successfully developed a parallel-series interleaved boost converter structure, that the primary sides of the double coupled inductors are connected in parallel at the input, and the secondary sides of the two coupled inductors are connected in series to achieve much higher voltage gain at the output. The working principle and steady-state characteristics 


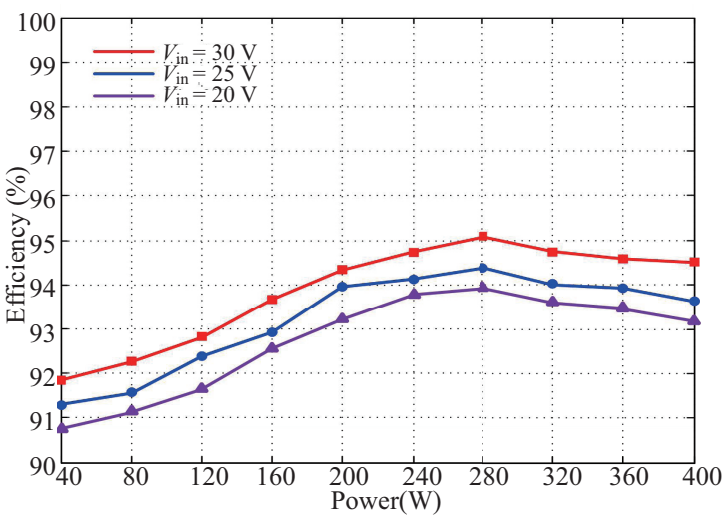

Fig. 16. The experimental efficiency curve of proposed converter.

of the converter are analyzed in detail and verified successfully. By using the technologies of interleaved input-parallel and output-series and voltage multiplier, the proposed converter has been implemented high step up conversion with high efficiency, low input current ripples, low output voltage ripples. The voltage stress of power devices is also very low, which will allow one to choose lower voltage rating MOSFETs and diodes to reduce both switching and conduction losses. In addition, because of the leakage inductance of coupled inductor, the power MOSFETs and output diodes are turned-on under zero current switching that not only reduce the switching losses but also help to conversion efficiency improvement.

\section{REFERENCES}

[1] Y. Shen, H. Wang, Z. Shen, Y. Yang, and F. Blaabjerg, "A 1-MHz series resonant DC-DC converter with a dual-mode rectifier for PV microinverters," in IEEE Transactions on Power Electronics, vol. 34, no. 7, pp. 6544-6564, July 2019.

[2] M. Islam, S. Mekhilef, and F. M. Albatsh, "An improved transformerless grid connected photovoltaic inverter with common mode leakage current elimination," 7th IET International Conference on Power Electronics, Machines and Drives (PEMD2014), Manchester, 2014, pp. 1-6.

[3] M. Moradzadeh, S. Hamkari, E. Zamiri, and R. Barzegarkhoo, "Novel high step-up DC/DC converter structure using a coupled inductor with minimal voltage stress on the main switch, " in Journal of Power Electronics, vol. 16, no. 6, 2016.

[4] M. Moradzadeh, H. Shadabi, and E. Babaei, "A novel DC-DC boost converter using capacitor multiplier for renewable energy applications," Power Electronics, Drive Systems \& Technologies Conference IEEE, 2017:184-188.

[5] H. Shojaeian, M. Heydari, and S. Hasanzadeh, "Improved interleaved high step-up converter with high efficiency for renewable energy applications," 2017 8th Power Electronics, Drive Systems \& Technologies Conference (PEDSTC), Mashhad, 2017, pp. 288-293.

[6] N. Rana, M. Kumar, A. Ghosh, and S. Banerjee, "A novel interleaved tristate boost converter with lower ripple and improved dynamic response," in IEEE Transactions on Industrial Electronics, vol. 65, no. 7, pp. 5456-5465, July 2018.

[7] H. Khoramikia, M. Heydari, and S. M. Dehghan, "A new three-port nonisolated DC-DC converter for renewable energy sources application," Electrical Engineering (ICEE), Iranian Conference on Mashhad, 2018, pp. 1101-1106.

[8] G. Wu, X. B. Ruan, and Z. Ye, "Non-isolated high step-up DC-DC converters adopting switched-capacitor cell," in IEEE Transactions on
Industrial Electronics, vol. 62, no. 1, pp. 383-393, 2015.

[9] T. Nouri, N. Vosoughi, S. H. Hosseini, and M. Sabahi, "A novel interleaved nonisolated ultrahigh-step-up dc-dc converter with ZVS performance," in IEEE Transactions on Industrial Electronics, vol. 64, no. 5, pp. 3650-3661, May 2017.

[10] M. Maalandish, S. H. Hosseini, and T. Jalilzadeh, "High step-up dc/ dc converter using switch-capacitor techniques and lower losses for renewable energy applications," in IET Power Electronics, vol. 11, no.10, pp. 1718-1729, Aug. 2018.

[11] S. Xiong and S. C. Tan, "Family of cascaded high-voltage-gain bidirectional switched-capacitor dc-dc converters," in Proceeding ECCE, Sept. 2015, pp. 6648-6654.

[12] Y. Tang, T. Wang, and Y. H. He, "A switched-capacitor-based activenetwork converter with high voltage gain," in IEEE Transactions on Power Electronics, vol. 29, no. 6, pp. 2959-2968, Jun. 2014.

[13] B. Wu, S. Li, K. M. Smedley, and S. Singer, "A Family of two-switch boosting switched-capacitor converters," in IEEE Transactions on Power Electronics, vol. 30, no. 10, pp. 5413-5424, Oct. 2015.

[14] H. C. Liu and F. Li, "A novel high step-up converter with a quasi-active switched-inductor structure for renewable energy systems," in IEEE Transactions on Power Electronics, vol. 31, no. 7, pp. 5030-5039, Jul. 2016.

[15] X. Liu, X. X. Hu, H. Chen, L. Z. Chen, and Y. J. Zhang, “An interleaved boost converter with parallel input and output series for renewable energy system," 2019 IEEE 10th international symposium on Power Electronics for Distributed Generation Systems (PEDG), Xi'an, 2019, pp. 995-1000.

[16] K. W. E. Cheng and Y. M. Ye, "Duality approach to the study of switched-inductor power converters and its higher-order variations," in IET Power Electronics, vol. 8, no. 4, pp. 489-496, Aug. 2015.

[17] Y. Tang, D. J. Fu, T. Wang, and Z. W. Xu, "Hybrid switched-inductor converters for high step-up conversion," in IEEE Transactions Industrial Electronics, vol. 62, no. 3, pp. 1480-1490, Mar. 2015.

[18] P. Wang, L. Zhou, Y. Zhang, et al, "Input-parallel output-series DC-DC boost converter with a wide input voltage range, for fuel cell vehicles," in IEEE Transaction on Vehicular Technology, vol. 66, no. 9, pp. 77717781, Sep. 2017.

[19] H. Q. Wen and B. Su, "Hybrid-mode interleaved boost converter designfor fuelcell electricvehicles," in Energy Conversion \& Management, vol. 122, pp. 477-487, Jun. 2016.

[20] W. Li, Y. Zhao, J. Wu, and X. He, "Interleaved high step-up converter with winding-cross-coupled inductors and voltage multiplier cells," in IEEE Transactions on Power Electronics, vol. 27, no. 1, pp. 133-143, Jan. 2012.

[21] K. C. Tseng, C. A. Cheng, and C. T. Chen, "High step-up interleaved boost converter for distributed generation using renewable and alternative power sources," in IEEE Journal of Emerging \& Selected Topics in Power Electronics, vol. 5, no. 2, pp. 713-721, Jun. 2017.

[22] A. Pevere, Alessandro, U. Chatterjee, and J. Driesen. "Current controller modeling for an interleaved boost with voltage multiplier cells for PV applications," Applied Power Electronics Conference and Exposition IEEE, 2016, pp. 1183-1190.

[23] H. Chen, C. Lu, and U. S. Rout, "Decoupled master-slave current balancing control for three-phase interleaved boost converters," in IEEE Transactions on Power Electronics, vol. 33, no. 5, pp. 3683-3687, May 2018.

[24] S. Chen, S. Yang, C. Huang, and S. Li, "Interleaved high step-up DCDC converter with three-winding coupled inductors for renewable energy system," 2018 IEEE International Conference on Industrial Electronics for Sustainable Energy Systems (IESES), Hamilton, 2018, pp. 124-129.

[25] T. Nouri, S. H. Hosseini, E. Babaei, and J. Ebrahimi, "Interleaved high step-up DC-DC converter based on three-winding highfrequency coupled inductor and voltage multiplier cell," in IET Power Electronics, vol. 8, no. 2, pp. 175-189, Feb. 2015. 


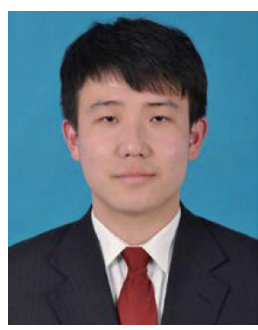

Xing Liu was born in Shandong, China, in 1994. He received his B.S. degree from the Nanyang Institute of Technology, Nanyang, China, in 2017. $\mathrm{He}$ is presently working towards his M.S. degree in the College of Electrical Engineering, Anhui University of Technology, Ma'anshan, China. His current research interests include power electronics, $\mathrm{dc}-\mathrm{dc}$ power conversion, and solar and wind power generation.

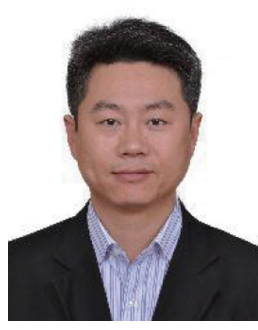

Xiao Zhang was born in Baoji, China, in 1974. He received his Ph.D. degree in Power Electronics and Electrical Drives in China University of Mining and Technology, Xuzhou, China, in 2012, In 1997, he joined the China University of Mining and Technology as a Teaching Assistant, where he has been an Associate Professor since 2009. His main research interests include electronic converters, electrical drive, power quality compensation systems, solid control of power system.

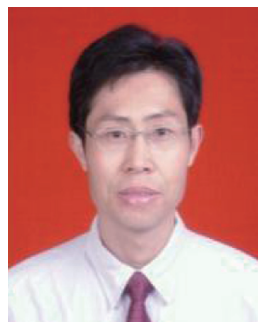

Xuefeng Hu received his M.S. degree in Electronic Engineering from the China University of Mining and Technology, Xuzhou, China, in 2001, and the Ph.D. degree in Electrical Engineering from the Nanjing University of Aeronautics and Astronautics (NUAA), Nanjing, China, in 2004.

$\mathrm{He}$ is presently working as a Professor in Anhui University of Technology, Ma'anshan, China. He is the author or coauthor of more than 40 technical papers. His current research interests include renewable energy systems, the modeling and control of converters, flexible ac transmission systems and distributed power systems.

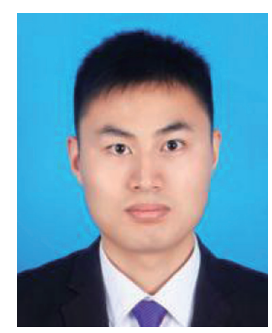

Hao Chen was born in Anhui, China, in 1991. He received his B.S. degree from Hefei Normal University, Hefei, China, in 2015. He is presently working towards his M.S. degree in the College of Electrical Engineering, Anhui University of Technology, Ma'anshan, China. His current research interests include power electronics, dc$\mathrm{dc}$ power conversion, the modeling and control of converters, and renewable power generation.

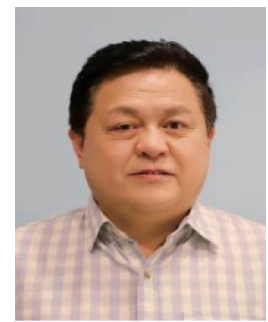

Lezhu Chen received the M.S. degree from University of Science and Technology Beijing, Beijing, China, in 1989. He is currently a professor at the College of Electrical Engineering, Anhui University of Technology, Ma'anshan, China. His current research interests include smart grid control, power qualitydetection and control, and application electronics.

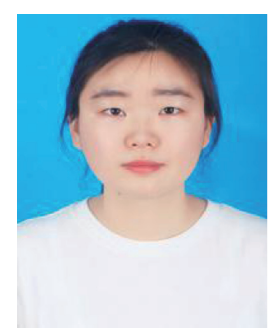

Yujia Zhang was born in Anhui, China, in 1996. She received the B.S. degree from the Industrial \& Commercial College, Anhui University of Technology, Ma'anshan, China, in 2018. She is currently working toward her M.S. degree at the College of Electrical Engineering, Anhui University of Technology, Ma'anshan, China. Her current research interests include power electronics, distributed power system, renewable power generation. 